\title{
Conservation and presentation of Neolithic Beidha, southern Jordan
}

\author{
Samantha Dennis, Bill Finlayson \& Mohammed NaJjaR*
}

The early Neolithic in the Levant, and specifically within Jordan, is critical to our understanding of the transition from hunter-gatherers to farmers, the beginnings of agriculture, the birth of religion and the emergence of community life. One of the most important changes directly documented in the material evidence is the rapid development of architecture associated with increasing sedentism and community size, both central to most models of the transition. Despite remarkably good preservation on some sites, construction techniques, overall form and function of the buildings remain poorly understood, severely limiting our understanding of important social developments.

One of the key early Neolithic sites in southern Jordan is Beidha, just $5 \mathrm{~km}$ north of Petra (FIGURE 1). It was excavated in the 1950s, '60s and ' 80 s by British archaeologist Diana HalbaekKirkbride (Kirkbride 1966a; 1966b; 1967; 1968; Byrd 1994). This revealed a series of complex occupation horizons from the Natufian and early Neolithic (Pre-Pottery Neolithic B). Unfortunately no conservation measures were taken during or after excavation and therefore the site, including standing walls and fragile plaster, is collapsing under the strain from livestock, tourists and weather. The Beidha Project was initiated in 2001 to conserve the site and present the complex remains to the public. The project is a joint collaboration between the Council for British Research in the Levant (CBRL) and the Department of Antiquities in Jordan with a strong emphasis on community involvement. Two local Bedouin tribes, the Ammarine and the B'dul, are involved at many levels from providing labourers to skilled craftmen, accommodation and site guards. Both have an interest in the long-term future of the site as a tourist attraction.

In addition to the routine conservation and presentation, a series of experimental reconstructions of Neolithic structures, based on evidence from the excavation, is being made. The first will also serve as a visitor centre (FIGURE 2). The project will examine the problems of conflicting interpretations made by archaeologists and of adapting these interpretations for a wider audience. These structures can help provide insights regarding the continuing debates concerning structure size and organization, function of individual buildings, site location, organization of interior space and inter-site variability over time. They will consequently help our understanding of significant patterns of social organization of settlement types, domestic activities and storage space and settlement population.

The first of a series of reconstructions is based on one of the earliest PPNB structures at Beidha. The semi-subterranean structure is $5 \mathrm{~m}$ in diameter with walls $1.20 \mathrm{~m}$ high and $0.50 \mathrm{~m}$ thick. The wall, built of stones from the wadi bed, consists of three main parts: inner wall, mud and stone fill and the outer wall, all built simultaneously to allow the mud and stone to bond (FIGURE 3). The timber roof, yet to be constructed, will be lashed to the upright timbers that have been placed within the stone wall (FIGURE 4).

Acknowledgements. We are grateful to the British Embassy in Amman for their support. We would also like to thank the many volunteers that helped carry hundreds of stones and a thank you to the Ammarine and B'dul for all their efforts and hospitality.

References

BYRO, B. 1994. Public and private, domestic and corporate: the emergence of the southwest Asian village, American Antiquity 59/4: 639-66.

KIRKBRIDE, D. 1960. The excavation of a Neolithic village at Seyl Aqlat, Beidha near Petra, Palestine Exploration Quarterly 92: 136-45.

1966a. Five seasons at the Pre-Pottery Neolithic village of Beidha in Jordan, Palestine Exploration Quarterly 98: 561.

1966b. Beidha, an early Neolithic Village in Jordan, Archaeology 19/3: 199-207.

1967. Beidha 1965: an interim report, Palestine Exploration Quarterly 99: 5-13.

1968. Beidha 1967: an interim report, Palestine Exploration Quarterly 100: 90-96.

\footnotetext{
* Dennis \& Finlayson, Council for British Research in the Levant, Po Box 519, Jubaiha 11941, Amman, Jordan. samjodennis@lycos.com director_cbrl@nets.com.jo Najjar, Department of Antiquities, PO Box 88, Jabal Amman, Amman, Jordan.
} 


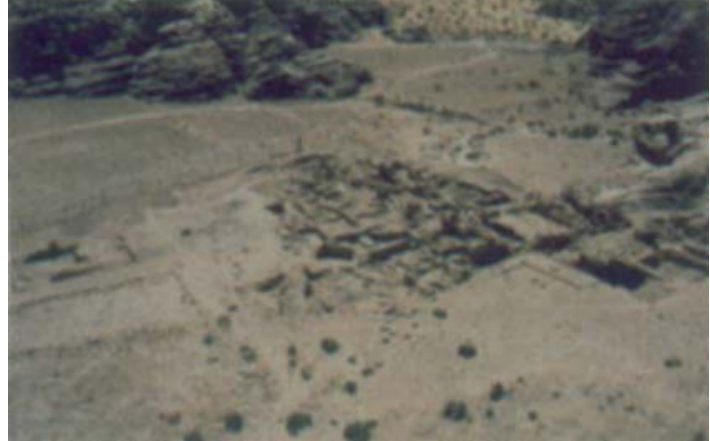

FIGURE 1. The early Neolithic site of Beidha, southern Jordan.

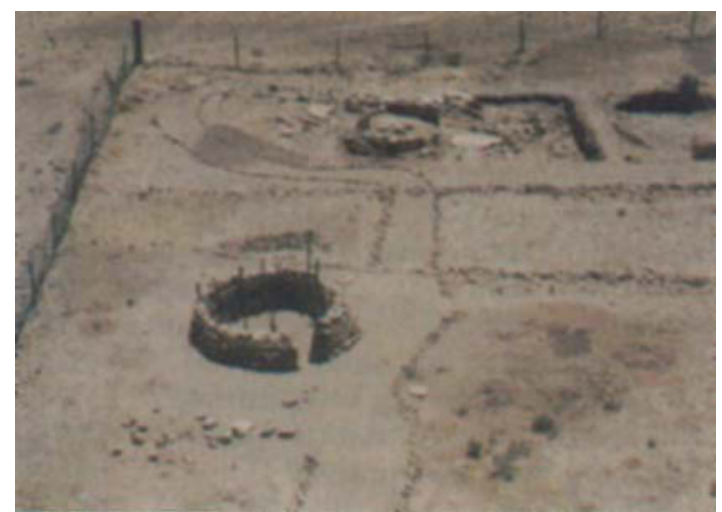

FIGURE 2. This aerial view of Beidha shows the experimental reconstruction in the foreground and the Neolithic remains behind, with pathways guiding visitors around the site.

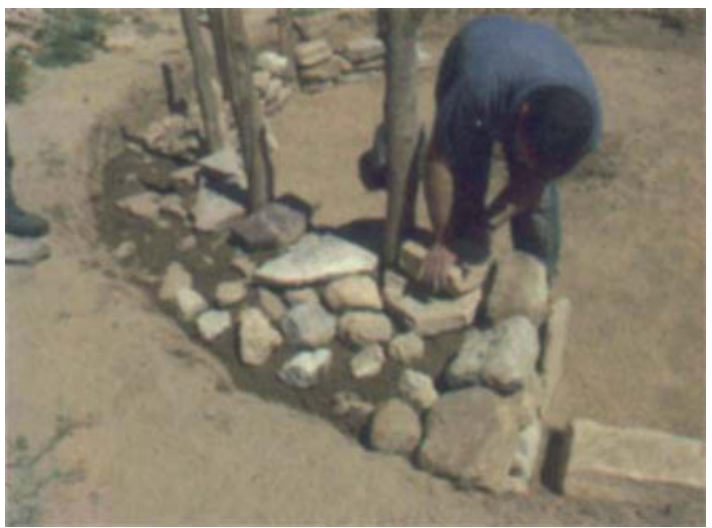

FIGURE 3. Experimental reconstruction of an early Neolithic wall, showing the timber framework, inner wall, and mud and stone fill.

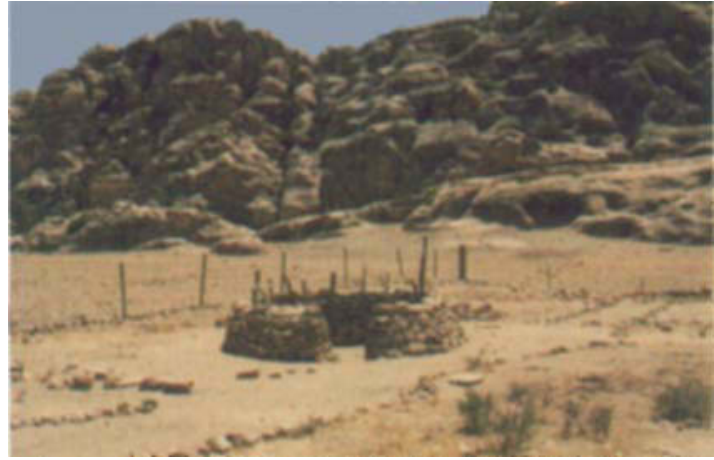

FIGURE 4. The experimental reconstruction before the roof was added.

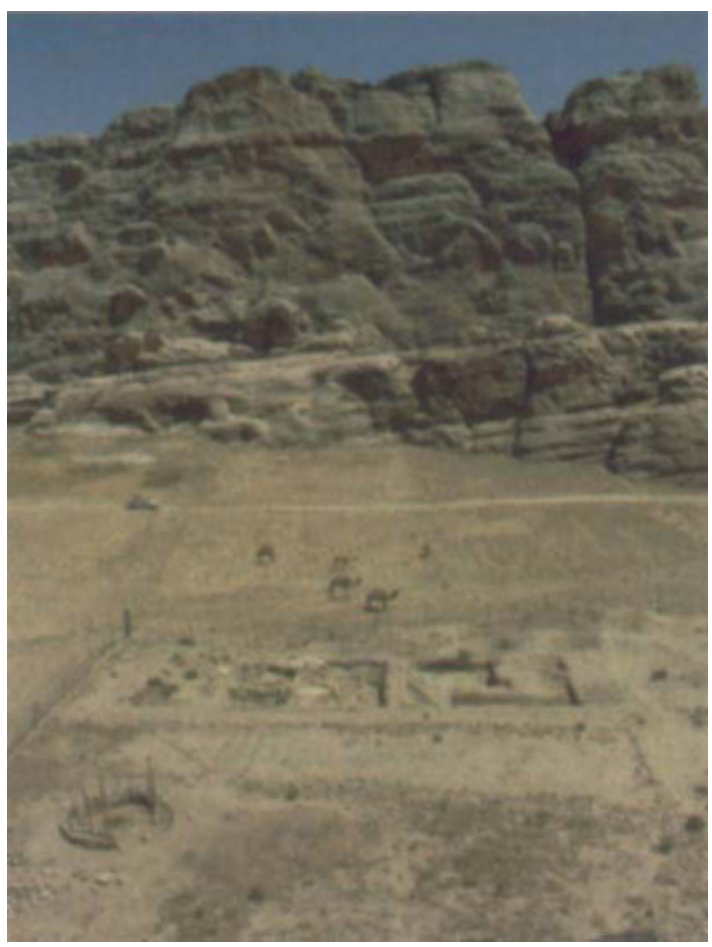

FIGURE 5. Aerial view looking south over Beidha. 